\title{
Algumas Considerações Sôbre a Chefia Qualificada
}

WAGNER ESTELITA CAMPOS

Ministro do Tribunal de Contas da Uniáo

Pede-me um artigo a Revista do Serviço Público, ora em fase de promissora renovação. O pedido me vem justamente num dos periodos mais trabalhosos de atividade no Tribunal de Contas da União.

Por isso mesmo não posso dar ao artigo a extensão e profundidade que desejara e a Revista positivamente merece.

É-me grato, entretanto, delinear algumas considerações sôbre matéria de minha particular predileção e ao estudo da qual venho me dedicando há mais de 25 anos, notadamente no âmbito da administração federal: o problema de chefia e liderança.

Através de livros e do magistério administrativo, além de conferências e debates em diversos setores civis e militares, na administração direta e indireta do Estado, em universidades, órgãos especializados como o IDORT e até na administração privada, procurei alcançar, sobretudo, dois objetivos: o de tentar uma sistematização dos aspectos fundamentais do problema, em seu conjunto, e o de despertar, para o mesmo, o interêsse dos administradores e estudiosos.

Até 1943 a matéria era objeto de limitado interêsse. Os Cursos de Administração do DASP criaram, àquela época, o curso de "Supervisão e Gerência de Serviços" (depois denominado "Problemas de Chefia") entregue aos meus cuidados durante 10 anos.

Posteriormente, a Escola Brasileira de Administração Pública (EBAP), da Fundação Getúlio Vargas, instituiu o curso de "Chefia Administrativa" (mais tarde denominado "Chefia e Liderança") igualmente entregue aos meus cuidados durante longo tempo, até minha vinda para Brasília como Deputado Federal, mandato que exerci durante oito anos, quatro dos 
quais como Presidente da Comissão de Orçamento da Câmara dos Deputados.

O assunto foi ganhando dimensões mais amplas, nas universidades, escolas de administração, inclusive as estaduais, instituições de ensino militar (que, aliás, sempre se preocuparam com o mesmo) e diversos setores da atividade privada, de ensino e administração.

Hoje a disciplina "Chefia e Liderança" integra o currículo de diversas universidades, escolas e cursos de administração e vai obtendo cada vez maior relevância nas mencionadas áreas de administração pública e privada, civil e militar, constituindo, quer em conjunto, quer em aspectos particulares (liderança de reuniões, por exemplo) objeto até mesmo do interêsse de numerosas emprêsas industriais e comerciais.

Por outro lado, a literatura administrativa brasileira sôbre o assunto, até 1947 contando apenas com meu livro (como estudo de conjunto), hoje apresenta algumas contribuições apreciáveis, embora quase tôdas abordando, apenas, aspectos parciais do problema.

Com o único propósito de assinalar o crescente interêsse pelo assunto e sem qualquer outra preocupação ou vaidade de ordem pessoal, permito-me assinalar que meu modesto livro - Chefia, Sua Técnica e Seus Problemas - atualmente em 5 a edição da Fundação Getúlio Vargas, vai alcançar, com a próxima edição da Biblioteca do Exército, um total de tiragem, computadas as edições anteriores, superior a 30.000 exemplares.

Note-se que durante largo período (1948 a 1963) não pude cuidar de outras edições, embora esgotada a $1^{a}$ em 1948, devido à natureza absorvente de atividades que mantive naquele período, sobretudo as de natureza parlamentar e política. Não fôra isso e certamente que seria ainda bem maior o mencionado total de tiragem do trabalho.

Isso evidentemente se deve menos aos méritos do livro que ao vulto do interêsse despertado pelo problema.

Mas tudo isso ainda não é o bastante para que devidamente se ampliem o estudo e a difusão de aspectos tão importantes da administração, quais os relativos à chefia e liderança.

Mister se faz que tôdas as universidades, escolas de administração e centros de aperfeiçoamento, nos diversos níveis federativos, incluam a disciplina "Chefia e Liderança" 
como obrigatória nos setores próprios dos respectivos currículos.

Mais que isso, é preciso que a referida disciplina ganhe o caráter de pré-requisito para os seminários e discussão objetiva dos problemas de chefia e liderança.

Tenho reiteradamente assinalado, e outros estudiosos também o fazem, que nenhum empreendimento de reforma administrativa conseguirá êxito sem que, simultâneamente, se atente para o problema e adequadamente se organizem os quadros de chefia.

Vale relembrar, num parêntese, que outro cuidado condiciona o êxito das reformas administrativas - o relativo à recuperação moral na função pública - como acentuam as palavras de François Houilliert, citadas pelo Embaixador Maurício Nabuco: "Les réformes administratives ne peuvent avoir d'efficacité que dans un climat nouveau, dans un effort de redressement d'abord moral".

Não bastam, entretanto, para que se organizem os quadros de chefia, a adoção, de imediato, de providências legislativas diretas sôbre o assunto.

Há um aspecto preliminar, envolvendo medidas de profundidade que produzam efeito a longo prazo: as relativas à formação de chefes, incluindo a vinculação, ao mesmo objetivo, do sistema educacional, em seus diferentes graus. Solução ideal, sem dúvida que difícil, mas que nem por isso deve deixar de ser perseguida.

Mas a realidade do funcionamento da máquina administrativa brasileira está a exigir solução urgente para o problema da escolha de chefes, em outras palavras, a efetiva adoção da chefia qualificada.

Abro aqui outro parêntese. Quando falo em chefia - têrmo genérico para designar a missão do dirigente em seus diferentes níveis - quero me referir tanto às funções gratificadas como aos cargos em comissão. respeito.

Nossa experiência, forçoso convir, tem sido precária a êsse

Anteriormente à Lei $n$ : 284, de 1936, os cargos de direção podiam ser providos em caráter efetivo e as chamadas funções de chefia constituiam, na maioria dos casos, final de carreira.

Referido diploma legal adotou o critério da "livre escolha baseada no fator confiança". 
Da rigidez de um critério passou-se à extrema elasticidade de outro, ambos apresentando vantagens e desvantagens, mas nenhum dos dois aceitável.

Dever-se-ia, de há muito, adotar a orientação de permitirse a "escolha" mas não "livre", senão que devidamente limitatada.

Em 1961, quando Deputado Federal, fiz uma tentativa nesse sentido, apresentando projeto de lei complementar (o de no 3.497), também subscrito pelo Deputado Raul Pila.

Nêle se criava, em cada Ministério civil, o cargo de secretário-geral administrativo, preenchivel por mandato de 3 anos, podendo haver recondução. Como condições para provimento do cargo exigia-se: ser funcionário público federal, com mais de 10 anos de serviço, sendo 5 , pelo menos, em função ou funções de direção de órgãos federais, estaduais, autárquicos ou da Prefeitura do Distrito Federal; ser titular efetivo de cargo da série de classes de oficial e técnico de administração, de classe singular ou série do serviço técnico-científico.

Entre outras, cometiam-se ao secretário-geral administrativo as atribuiçöes de "supervisão geral dos serviços do Ministério para o fim de preservar a continuidade administrativa" e de indicar, em lista tríplice, os ocupantes dos cargos de direção do respectivo Ministério.

Os cargos de direção superior, como os de direção intermediária, sòmente poderiam ser exercidos por servidores públicos federais, sendo necessário, para o provimento dos cargos de direção superior, o requisito de tirocínio administrativo de, pelo menos, dois anos em função ou funções de direção de órgãos federais ou dos demais já enumerados.

Previa-se, também, que os regulamentos das repartições pudessem fixar, em cada caso, quando necessário, requisitos de ordem profissional.

Tratava-se de assegurar a independência e a continuidade da máquina administrativa, tendo em vista o sistema parlamentar de govêrno, então adotado, menos pròpriamente como sistema - que não vingou - que como medida de ordem política para contornar a grave crise surgida àquela época.

Como ficou claro na justificação do projeto, êle representava medida de emergência, já que a solução definitiva estaria na dependência de uma correta classificação de cargos. 
O projeto não vingou, precisamente porque fixava limites à liberdade de escolha que se desejava manter.

A atual lei de reforma administrativa (Decreto-lei $n \div 200$, de 1967), já contém dispositivos e normas que visam ao salutar propósito de adotar-se a chefia qualificada.

Vale transcrever os seguintes preceitos:

"Art. 101. O provimento em cargos em comissão e funções gratificadas obedecerá a critérios a serem fixados por ato do Poder Executivo que:

a) definirá os cargos em comissão de livre escolha do Presidente da República;

b) estabelecerá os processos de recrutamento com base no Sistema do Mérito; e

c) fixará as demais condições necessárias ao seu exercício.

§ 10 Em conseqüência do disposto no inciso III dêste artigo, os funcionários que atenderem às condições estipuladas ficam sujeitos ao regime de 40 (quarenta) horas semanais de trabalho e perceberão gratificação pelo regime de tempo integral e dedicação exclusiva.

$\S 2$. E inerente ao exercício dos cargos em comissão e funções gratificadas diligenciar seu ocupante no sentido de que se aumente a produtividade, se reduzam os custos e se dinamizem os serviços.

"Art. 121. As medidas relacionadas com o recrutamento, seleção, aperfeiçoamento e administração do assessoramento superior da Administração Civil, de aperfeiçoamento de pessoal para o desempenho dos cargos em comissão e funções gratificadas a que se referem o art. 101 e seu inciso II (Título XI, o Capítulo II) e de outras funções de supervisão ou especializadas, constituirão encargos de um Centro de Aperfeiçoamento, órgão autônomo, vinculado ao Departamento Administrativo do Pessoal Civil.

Parágrafo único. O Centro de Aperfeiçoamento promoverá, direta ou indiretamente, mediante convênio, acôrdo ou contrato, a execução das medidas de sua atribuição." 
Infelizmente, porém, tanto quanto seja de meu conhecimento, tais dispositivos não vêm sendo devidamente aplicados.

Cito, exemplificativamente, o fato de que o Centro de Aperfeiçoamento, previsto no art. 121, ainda não se encontra estruturado definitivamente, sem embargo das providências, que, ao que sei, estão sendo encaminhadas.

A solução do problema da chefia qualificada, repito, continua na dependência de adequada classificação de cargos, convenientemente posta em prática. Até que isso ocorra não se obterão as condições necessárias a um critério correto de provimento dos cargos em comissão e funções gratificadas e não se poderá proceder a uma salutar limitação na área de escolha de chefes.

Tal providência deverá, òbviamente, ser acompanhada de política firmemente orientada no sentido de fortalecimento do sistema do mérito.

Como tenho acentuado em diversas oportunidades, estivemos à beira de dar o primeiro passo para a desejada solução do problema.

O Plano de Classificação de Cargos, remetido pelo Poder Executivo ao Congresso Nacional através da Mensagem no 398 , de 6 de setembro de 1954, enfrentou corajosamente, como acentuou Kleber Nascimento, "o propósito da formação de quadros regulares de chefia, eliminando a função gratificada para a chefia de seção, cujas atribuições passariam a ser específicas da Classe " $\mathrm{C}$ " da série de classes que guardasse correspondência com a função por desempenhar, mediante gratificações complementares".

Abria-se, por outro lado, a meu ver, a perspectiva de, no acesso do nivel " $B$ " para o nivel " $C$ " aproveitar-se, de futuro, a experiência da seleção científica, já realizada em outros países, aferindo-se os fatôres aptidão, eficiência e personalidade.

Além do mais, a boa solução para o preenchimento das funções gratificadas poderia fixar condições para convenientes limitações na área do provimento dos cargos em comissão.

Mas o plano remetido em 1954 infelizmente não vingou. De tal forma foi desvirtuado em sua tramitação legislativa que, afinal, deixou de ser um plano de classificação, dada a integral quebra do sistema e não houve esfôrço que impedisse um resultado inteiramente inaceitável do ponto de vista técnico e financeiro. 
Participei dêsse esfôrço, na esfera legislativa, integrando, na Câmara, uma subcomissão da Comissão de Finanças, como antes havia participado da elaboração do plano, na esfera do Executivo, membro que fui da Comissão designada pelo Govêrno.

O desfecho de um trabalho penosamente elaborado foi melancólico: a única solução possível foi a da adoção de um simples reajustamento de vencimentos. de 1960.

Elaborou-se nôvo plano, afinal aprovado pela Lei no 3.780 ,

Mas êsse segundo plano, no que toca ao problema da formação de quadros de chefia, abandonou propósitos fundamentais do plano anterior, que, de resto, era muito melhor e apresentava estrutura menos vulnerável.

Basta assinalar, exemplificativamente, que a classe " $C$ " do plano anterior foi suprimida.

Por outro lado, vale considerar que o art. 12 da mencionada Lei no 3.780, de 1960, determinou que o Poder Executivo regulamentasse a classificação das funções gratificadas com base, entre outros, "nos princípios de hierarquia funcional, analogia das funções, importância, vulto e complexidade das respectivas atribuições". O parágrafo único do referido art. 12 mandava também prever, na regulamentação, a "correlação fundamental entre as atribuições do cargo efetivo do funcionário e da função gratificada para que fôr designado".

Dando cumprimento a êsse mandamento, foi baixado o Decreto no 49.592, de 1960, no qual era rìgidamente estabelecido 0 critério da correlação.

Posteriormente, porém, o Decreto no 50.572 , de 1961, dispensou a observância da correlação indicada nas tabelas do anexo do decreto anterior, até que se adotassem as providências previstas (aprovação, em caráter definitivo, da classificação das funções gratificadas do Serviço Civil do Poder Executivo e especificações de classe (art. $60^{\circ}$ da Lei n’ 3.780 , de 1960).

Como até agora não foram tomadas as referidas providências, continua inobservada a correlação, o que não permite atingir-se, de maneira desejada, o propósito da chefia qualificada.

Desejo mais uma vez observar que o referido propósito não deve limitar-se ao nivel das funções gratificadas, mas também alcançar o dos cargos em comissão, o que certamente será ob- 
jeto de especiais cuidados do Centro de Aperfeiçoamento, órgão a que incumbe o estudo e encaminhamento de medidas relacionadas com o "recrutamento, seleção e aperfeiçoamento de pessoal para o desempenho dos cargos em comissão".

Recordo, a propósito, que defendo, em meu livro, entre outras, providências que visem, em síntese, a:

a) fixação, na classificação de cargos, de um nível final de onde devam ser escolhidos os chefes intermediários;

b) acesso ao nível referido mediante apuração, pelos meios próprios, das condições de aptidão, eficiência e personalidade;

c) criação do nível de chefia superior, provendo-se os respectivos cargos, através da escolha entre os chefes intermediários, mediante a observância, entre outros, de requisitos de ordem técnica e profissional e diplomação em cursos especializados para chefes dessa categoria.

Isso sem falar em outras sugestões, inclusive a da criação do cargo de secretário-geral administrativo, escolhido, através de requisitos próprios, dentre os titulares dos cargos de chefia superior.

Tentar-se-ia, assim, o estabelecimento de uma hierarquia racional entre os cargos e funções de chefia, objetivo que òbviamente não é viável no momento, mas pode constituir uma perspectiva para o futuro.

Em face de todo o exposto e, ainda, de longa, embora modesta experiência no trato do assunto, é que tive particular satisfação em verificar que constam das "diretrizes setoriais na área da administração federal", que me foram entregues pelo Diretor-Geral do DASP, Dr. Glauco Lessa de Abreu e Silva, dois itens, a saber:

a) como diretriz específica, a "formação qualitativa e quantitativa dos quadros dirigentes da Administração Civil"; $e$

b) entre as "medidas administrativas", a referente à "fixação de diretrizes", para a elaboração de um nôvo "plano de classificação de cargos e empregos".

Para a obtenção do primeiro objetivo - "formação qualitativa e quantitativa dos quadros dirigentes" - muito poderão contribuir, certamente, a estrutura definitiva e uma atividade intensa do Centro de Aperfeiçoamento previsto no art. 121 do Decreto-lei n? 200/67. 
Quanto à classificação de cargos, espero que não apenas as diretrizes respectivas logo se estabeleçam como, igualmente, se transformem em breve realidade.

Sòmente assim poderemos ter, afinal, no serviço civil brasileiro, o instrumento básico e indispensável para o desenvolvimento de tôdas as etapas da administração de pessoal, inclusive a da adoção do princípio da chefia qualificada, em todos os níveis e escalões.

São os meus votos. Tenho esperança de que êles sejam transformados em realidade, no prazo mais breve possivel.

Ainda que assim não seja, é preciso considerar que na missão do estudioso se inclui também aquela "capacidade de espera", que, segundo Pigors, define um dos aspectos do moral do grupo.

Relembro, a êsse respeito, que, em 1953 - há 17 anos, portanto - preconizei, em conferência pronunciada na Escola Superior de Guerra, a adoção de cinco medidas de ordem administrativa, tôdas a meu ver fundamentais, mas que sòmente se concretizaram em 1966, 1967 e 1969, uma na lei ordinária e quatro na Constituição de 1967 ou na Emenda Constitucional no 1, de 1969.

Prescindo de sua enumeração, o que poderei fazer em outra oportunidade, porque mencionadas medidas não guardam relação direta com os temas dêste artigo.

Mas tal espaço de tempo não ocorrerá certamente agora, pois que se trata de medidas em curso, já objeto das cogitações do legislador e do administrador.

Basta que haja pertinácia e continuidade de esforços sistematizados e certamente atingiremos um dia, que pode não estar longe, o ideal da chefia qualificada. 


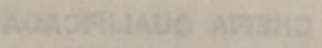

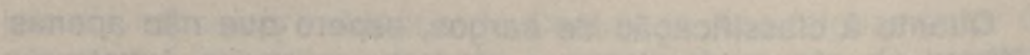

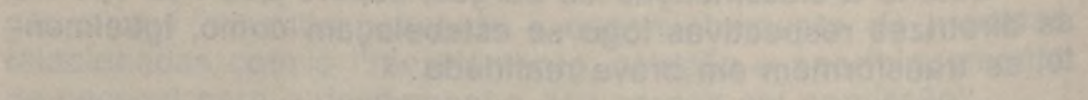

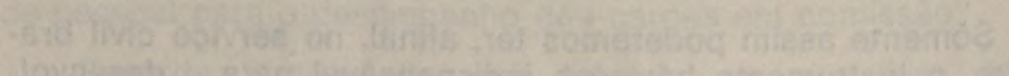

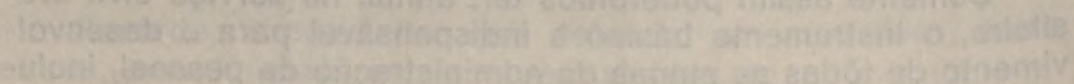

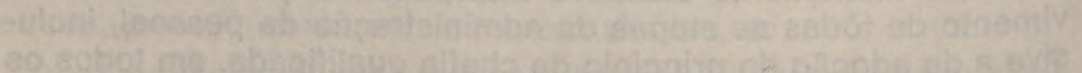

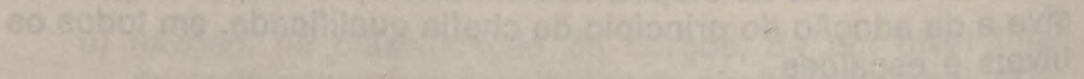

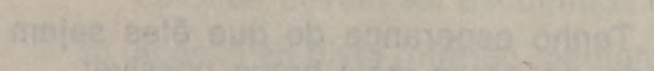

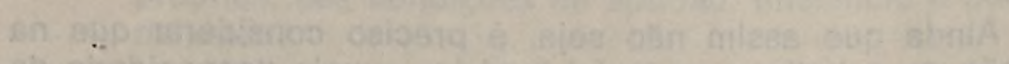

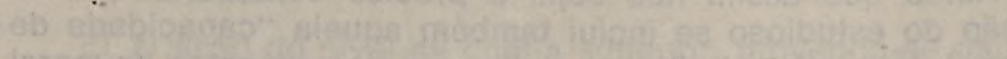

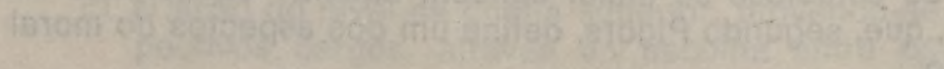

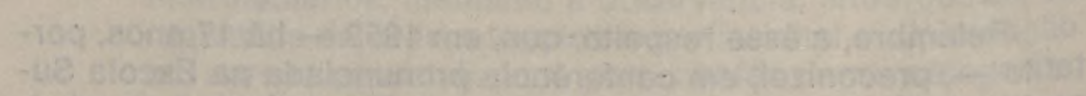

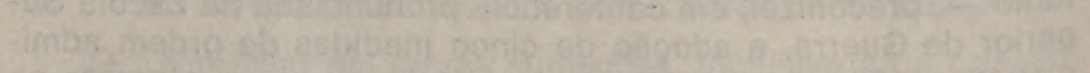

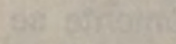

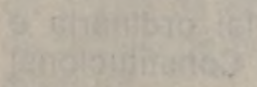
anc

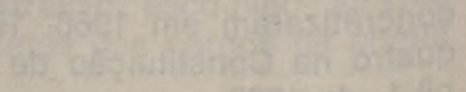

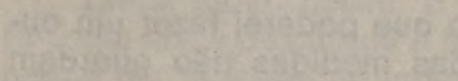

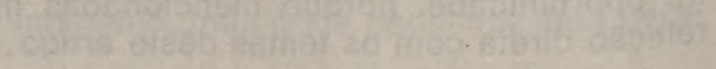

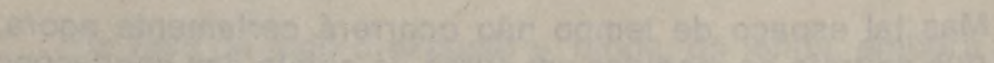

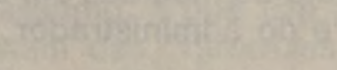

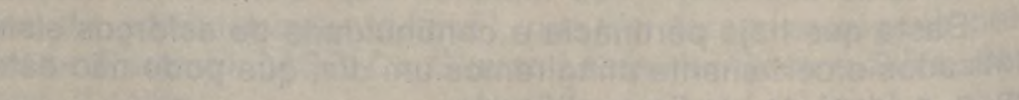

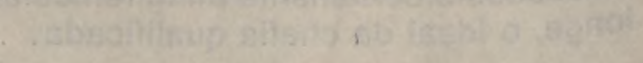

